\title{
A RESERVA DE MERCADO, NO BRASI, PARA A PRODUÇÃO DE BENS DE INFORMÁTICA
}

\author{
Eros Roberto Grau \\ Professor Doutor da Faculdade de Direito da Universidade de São Paulo
}

\begin{abstract}
Resumo: Exposição das razões que justificam a institucionalização da reserva de mercado, no Brasil, para a produção dos bens de informática. Descrição da lei que institui uma Política Nacional de Informática no Brasil. Análise do instituto jurídico da reserva de mercado e do conceito de empresa nacional, destacando-se especialmente a noção de controle tecnológico e-os contratos de joint venture. Enunciação dos efeitos da Política Nacional de Informática e da reserva de mercado neste setor da economia brasileira.
\end{abstract}

Résumé: Mostrer les raisons que ont fondé la reserve de marché, au Brésil, pour la production des bens de l'informatique. Description de la loi qu'a introduit la Politique Nationale de l'Informatique. Faire l'analise de l'institut juridique de la reserve de marché et de la notion de entreprise nationale, de la notion de contrôle tecnologique et de contrat de "joint venture". Enoncer les effets de la reserve de marché dans ce secteur de l'economie.

Unitermos: Política Nacional de Informática; Conceito Legal de Empresa Nacional.

Este trabalho é uma tradução do texto Market Reserve in Brazil on the Production of Informatic Goods, apresentado no $4^{2}$ Congresso Internazionale Sul Tema Informatica e Regulamentazioni Giuridiche em Roma, maio de 1988.

I - Razöes que justificaram a institucionalização da reserva de mercado, no Brasil, para a produção de bens de informática ${ }^{(1)}$.

01. A "modernização" da sociedade brasileira conduziu-a, tal como ocorre com as demais sociedades subdesenvolvidas, a uma situação de dependência em relação às sociedades desenvolvidas.

Um dos sintomas mais evidentes dessa dependência encontra-se na dissociação entre a sofisticação da tecnologia usada e a pobreza daquela concebida ou concebível pela sociedade que se tem como dependente. Nosso processo de industrialização, expressão de um "capitalismo tardio", verificou-se, a partir da década quarenta, segundo um modelo que colocava nossos agentes econômicos na situação de verdadeiros intermediários entre os produtores estrangeiros e o mercado. Isso fez com que nos tornássemos um país usuário de tecnologia e levou à transformação de nossas indústrias em meras agentes, "comerciais", de repasse, ao consumidor, dessa tecnologia importada. 
A consolidação, nos anos sessenta, das corporações multinacionais (CMNs) no mercado internacional conferiu nitidez plena ao papel que as sociedades subdesenvolvidas assumiam, de consumidoras de tecnologia externa.

02. A idéia de "modernização", ela própria contribuía como contribui - à perenização desse papel. $\mathrm{Na}$ medida em que, supondo a "profanização" da cultura ocidental, sustenta-se sobre a organização da empresa capitalista (ainda que também sobre a organização do Estado-aparato, se bem que este à serviço daquela), a "modernização" impôe a institucionalização de um agir econômico (e administrativo) orientado pela racionalização voltada aos fins (Zweckrationalitat) $^{(2)}$.

No quadro ideológico da "modernização", a racionalidade da divisão internacional do trabalho leva naturalmente à condenação de toda e qualquer tendência à utilização de tecnologia local, pelas sociedades subdesenvolvidas, ou esforço para concebê-la, como "irracional".

Nesse mesmo quadro, por outro lado, os conceitos de Estado e de nação são apontados como obstáculos ao desenvolvimento, de modo que, sempre, a afirmação da busca de desenvolvimento tecnológico local é contestada sob o argumento de que o nacionalismo é retrógrado.

As críticas que se pode opor a tal ideologia são inúmeras, não sendo este, por certo, o momento adequado para delas cuidarmos. Rememoro tão-somente até porque, tal como a língua, a tecnologia é um elemento antropológico - o argumento de Cláudio Mammana ${ }^{(3)}$ : a nação é uma globalidade antropológica semelhante a um animal, como unidade biológica; funções digestivas não podem ser repartidas entre diferentes animais, a alguns deles sendo atribuída a de comer e, a outros, a de digerir; o que sucede com os animais também sucede com as nações; o que aquela divisão internacional do trabalho propõe é antropologicamente inconcebível.

De toda sorte, não apenas naquele quadro ideológico, mas também na praxis hegemônia por ele informada, ainda que diante de tecnologias primitivas a engenharia local possa efetivamente participar do processo de sua concepção, finda por restar definitivamente alijada do processo produtivo quando a tecnologia é mais sofisticada.

03. Até a década setenta, no Brasil, a dissociação entre tecnologia usada e tecnologia concebida internamente era artificialmente tolerável. Uma série de fatores, todavia, passou a atuar, então, dando lugar a tentativas de sua superação.

Com o advento da crise do petróleo e das crises financeiras que àquela se seguiram ficaram evidentes as desvantagens que tal dissociação acarretava para a economia nacional.

Países com mão-de-obra cara expelem capitais para países de mão-de-obra barata. Quando o preço desta se eleva, no entanto, dá lugar à automação e à redução das atividades das CMNs nos países subdesenvolvidos. Isso decorre, de uma parte, do processo, ainda que sempre lento, de efetivaçäo dos "direitos sociais", que as constituições, na sociedade capitalista, contemplam em termos meramente programáticos, despidos de eficácia ${ }^{(4)}$. De outra parte, a melhoria dos produtos, 
mediante o emprego de menor número de componentes, e a automação dos processos produtivos, fruto do desenvolvimento tecnológico, inarredavelmente induz aquela redução de atividades.

Além disso, ainda o desenvolvimento tecnológico permitiu a substituição de matérias-primas naturais por materiais sintéticos. Essa substituição, marcante em relação ao cobre, ao aço, às fibras naturais, por exemplo, só não se tornou ainda possível em relação ao petróleo.

Como a economia brasileira era baseada na exploração de mão-de-obra não qualificada barata e cumprimos a função de exportadores de matérias-primas, o advento da crise do petróleo, associado ao surto de desenvolvimento tecnológico então produzido, nos fez conscientes de que não nos manteríamos como participantes da economia mundial se não fôssemos capazes de produzir desenvolvimento tecnológico.

Isso se impunha, ademais, em virtude de a história da nossa indústria eletrônica ser inteiramente diversa da história da indústria eletrônica nos países do Sudeste Asiático. Neste campo, ainda que a influência da eletrônica sobre outros setores econômicos seja extremamente importante, estivemos sempre a privilegiar as importações, sem que nos empenhássemos no efetivo desenvolvimento da indústria de componentes. A inexistência de- uma política responsável na Zona Franca de Manaus importou em que resultassem extremamente elevados os custos de produção de nossos produtos de tecnologia eletrônica.

04. Assim, no início da década sessenta, a convicção de que a engenharia nacional era detentora da capacidade suficiente para produzir minicomputadores, com o apoio dos resultados de pesquisas que o Instituto Tecnológico de Aeronáutica (ITA), a Escola Politécnica da Universidade de São Paulo e a Pontifícia Universidade Católica do Rio de Janeiro empreendiam, uniu, no seio da Administração Páblica Federal, alguns engenheiros brasileiros, muitos dos quais com estudos de pós-graduação nos Estados Unidos. $O$ que os unia era o interesse comum na implantação do desenvolvimento tecnológico, no setor da informática, no país ${ }^{(5)}$. Inicialmente, em 1971, em um grupo de trabalho, já no ano seguinte em uma comissão do Ministério do Planejamento - Coordenação de Atividades de Processamento Eletrônico (CAPRE) - esse grupo, que tem sido referido como de "guerrilheiros ideológicos", plantou as raízes institucionais da futura evolução da indústria brasileira de computadores.

Interessava especialmente à Marinha brasileira essa evolução, preocupada com o fato de que a modernização dos equipamentos militares ao seu dispor a deixava sob dependência da tecnologia estrangeira no setor. De outra parte, a modernização da burocracia federal, mediante a criação do SERPRO, empresa sob o controle do Ministério da Fazenda, reclamava a disponibilidade de hardware local. A experiência de trinta anos de transferência de tecnologia, com a qual acenavam as CMNs instaladas no Brasil, demonstrava que essa "transferência" consubstanciava verdadeiro estelionato tecnológico ${ }^{(6)}$. 
A CAPRE passou a exercer o controle das importações de componentes e, com isso, reproduziu a mecânica de reserva de mercado de fato que, há anos, já se institucionalizara no Brasil, em favor das CMNs, no setor automobilístico. Apenas, agora, a reserva era estabelecida em benefício da indústria nacional.

Uma série de outros fatores, então, prosperou no sentido de reforçar-se, institucionalmente, a atuação do estado como ordenador do mercado nacional de informática.

O mercado dos microcomputadores - mercado não reivindicado, na época, pela CMNs ampliou-se de modo marcante a partir da segunda metade dos anos setenta. Ainda que a política dos "guerrilheiros ideologicos" estivesse originariamente voltada à capacitação nacional para a produção de minicomputadores, atuava agora em benefício da consolidação da indústria de microcomputadores. Daí, então, o posicionamento do capital nacional, caudatário dela, em favor da sustentação dessa política - no que se encontra confirmação da tese segundo a qual, no Brasil, o empresariado privado deixa sempre ao Estado a iniciativa da busca de caminhos econômicos inovadores.

De outra parte, como observa Evans (7), dado que a tecnologia do microcomputador estava incorporada em chips, as barreiras tecnológicas para a transferência dela eram bem poucas. Devido à disponibilidade dos microprocessadores, a construção de um micro exigia capacitação tecnológica, mas não estava de modo algum fora do alcance de um engenheiro eletrônico com formação avançada. Como os microprocessadores eram produzidos por companhias de semicondutores que não produziam computadores - prossegue Evans - eles eram encontrados como uma mercadoria comum e não incorporados a produtos de demanda final como tecnologia patenteada.

Ao lado de tudo isso, o relatório francês elaborado, no final da década setenta, por Simon Nora e Alain Minc, antecipando a fusão das telecomunicações com a informática, chamava a atenção para a importância desta última e sua estrita vinculação aos ideais de segurança nacional ${ }^{(8)}$.

O clima da ditadura militar que sofremos, buscando legitimidade em uma doutrina da segurança nacional, ensejou então, no final da década, a substituição da CAPRE pela Secretaria Especial de Informática - SEI. A esse tempo ainda, já na década oitenta, é sancionada a Lei $\mathbf{n}^{\ell} 7.232$, que institui a Política Nacional de Informática.

\section{II - A Lei n² 7232, de 29 de novembro de 1984}

05. A Lei $n^{0} 7.232 / 84$ estabelece o objetivo, os princípios e diretrizes da Política Nacional de Informática, seus fins e mecanismos de formulação, cria o Conselho Nacional de Informática e Automação, CONIN, dispõe sobre a Secretaria Especial de Informática (SEI), cria os distritos de Exportação de Informática, autoriza a criação da Fundação Centro Tecnológico para Informática (CTI), institui o Plano Nacional de Informática e Automação e o Fundo Especial de Informática e Automação. 
O seu artigo $2^{2}$ define que "a Política Nacional de Informática tem por objetivo a capacitação nacional nas atividades de informática, em proveito do desenvolvimento social, cultural, político, tecnológico e econômico da sociedade brasileira. atendidos os seguintes princípios:

I - ação governamental na orientação, coordenação e estímulo das atividades de informática;

II - participação do Estado nos setores produtivos de forma supletiva, quando ditada pelo interesse nacional, e nos casos em que a iniciativa privada nacional não tiver condições de atuar ou por eles não se interessar;

III - intervenção do Estado de modo a assegurar equilibrada proteção à produção nacional de determinadas classes e espécies de bens e serviços como crescente capacitação tecnológica;

IV proibição à criação de situações monopolíticas, de direito ou de fato;

V ajuste continuado do processo de informatização às peculiaridades da sociedade brasileira;

VI - orientação de cunho político das atividades de informática, que leve em conta a necessidade de preservar e aprimorar a identidade cultural do País, a natureza estratégica da informática e a influência desta no èsforço desenvolvido pela Nação, para alcançar melhores estágios de bem-estar social;

VII direcionamento de todo o esforço nacional no setor, visando atendimento dos programas prioritários do desenvolvimento econômico e social e ao fortalecimento do Poder Nacional, em seus diversos campos de expressão;

VIII - estabelecimento de mecanismos e instrumentos legais e técnicos para a proteção do sigilo dos dados armazenados, processados e veiculados, do interesse da privacidade e de segurança das pessoas físicas e jurídicas, privadas e públicas;

IX - estabelecimento de mecanismos e instrumentos para assegurar a todo cidadão o direito ao acesso e à retificação de informaçōes sobre ele existentes em bases de dados públicas ou privadas;

$X$ - estabelecimento de mecanismos e instrumentos para assegurar o equilibrio entre os ganhos de produtividade e os níveis de emprego na automação dos processos produtivos;

$\mathrm{XI}$ - fomento e proteção governamentais dirigidos ao desenvolvimento de tecnologia nacional e ao fortalecimento econômico-financeiro e comercial da empresa nacional, bem como estímulo à redução de custos dos produtos e serviços, assegurando-lhes maior competitividade internacional."

Está contemplada, neste artigo $2^{2}$, uma norma-objetivo, ou seja, norma que não define conduta nem orgnizaçäo, mas que determina, fixando-os, fins a serem alcançados. A consagração, no ordenamento jurídico, de normas como tais $\varepsilon$ de importância fundamental. Tal ocorre desde o instante em que o Direito passa a ser dinamizado como um instrumento de governo e deixa de ser sua finalidade, única e exclusivamente, a de ordenação. Enquanto instrumento de governo, agora, o Direito passa a ser atuado tendo em vista a implementação de políticas, políticas estas referidas a fins múltiplos e específicos. Essas normas jurídicas de novo tipo, pois, estão voltadas à definição jurídica desses múltiplos e específicos fins: Assim, operam a metamorfose de fins sociais e econômicos - políticos - em jurídicos. À propósito, 
não será demais repetir, com Thering ${ }^{(9)}$, que "não existe nenhuma norma jurídica que não deva sua origem a uma finalidade, isto é, a um motivo prático". De outra parte, é de relevância extrema observarmos que a circunstância da contemplação delas no ordenamento jurídico importa no comprometimento da atividade da hermenêutica com os fins nelas inscritos: definidos os fins de determinado conjunto normativo, é imperiosa, tal como ocorre em relação à Lei $n^{\mathbb{Q}} 7.232 / 84$, a necessidade de conferir-se interpretação teleológico às normas de conduta e de organização que o compõem ${ }^{(10)}$.

$\mathrm{O}$ artigo $3^{2}$ da Lei $n^{2} 7.232 / 84$ define quais as atividades que, para os seus efeitos, são consideradas como de informática e o artigo $4^{2}$ enuncia os instrumentos da Política Nacional de Informática.

06. O que ora importa objetivamente considerar, de toda sorte, é o preceito contido no artigo $9^{2}$ da Lei $n^{\mathbf{9}} 7.232 / 84$ que, complementando-se em seus dois parágrafos e no artigo 10, institui a reserva de mercado para a produção de bens de informática, no Brasil. Dado que a disposição contida naquele preceito está diretamente referida à conceituação legal de empresa nacional, inscrita no artigo 12 da lei, é oportuna a transcrição de todos os artigos e parágrafos mencionados no presente texto:

"Art. 92 Para assegurar adequados níveis de proteção às empresas nacionais, enquanto não estiverem consolidadas e aptas a competir no mercado internacional, observados criterios diferenciados segundo as peculiariedades de cada segmento especifico de mercado, periodicamente reavaliados, o Poder Executivo adotará restriçōes de natureza transitória à produção, operação, comercialização, e importação de bens e serviços técnicos de informática.

$\S 1^{2}$ - Ressalvado o disposto no artigo 10 , não poderão ser adotadas restrições ou impedimentos ao livre exercício da fabricação, comercialização e prestação de serviços técnicos no setor de informática às empresas nacionais que utilizem tecnologia nacional, desde que não usufruam de incentivos fiscais e financeiros.

$\S 2^{2}$ - Igualmente não se aplicam as restrições do "caput" deste artigo aos bens de informática, com tecnologia nacional, cuja fabricação independe da importação de partes, peças e componentes de origem externa."

"Art. 10 - O Poder Executivo poderá estabelecer limites à comercialização, no mercado interno, de bens e serviços de informática, mesmo produzidos no País, sempre que ele implique na criação de monopólio de fato em segmentos do setor."

"Art. 12 - Para os efeitos desta Lei, empresas nacionais são as pessoas jurídicas constituídas e com sede no País, cujo controle esteja, em caráter permanente, exclusivo e incondicional, sob a titularidade, direta ou indireta, de pessoas físicas residentes e domiciliadas no País, ou por entidades de direito público interno, entendendo-se controle por:

I - controle decisório: o exercício, de direito e de fato, do poder.de eleger administradores da sociedade e de dirigir o funcionamento dos órgãos da empresa;

II - controle tecnológico: o exercício, de direito e de fato, do poder para desenvolver, gerar, adquirir e transferir e variar de tecnologia de produto e de processo de produção; 
III - controle de capital: a detenção, direta ou indireta, da totalidade do capital, com direito efetivo ou potencial de voto, e de, no mínimo, $70 \%$ (setenta por cento) do capital social."

\section{III - A reserva de mercado e conceito de empresa nacional}

07. À SEI, que é órgão subordinado ao CONIN, é atribuída, além de outras, as funções de adotar as medidas necessárias à execução da Política Nacional de Informática, no que lhe couber, de analisar e decidir sobre os projetos de desenvolvimento e produção de bens de informática e de manifestar-se previamente sobre as importaçōes de bens e serviços de informática por oito anos a contar de $\mathbf{3 0}$ de outubro de 1984, atendidas as resoluções a respeito da matéria expedidas pelo CONIN (artigo $8^{2}$, IV, V, e VI da Lei $n^{2} .7 .232 / 84$ ).

A ela incumbe, assim, autorizar a instalação, no país, de indústrias de bens de informática, o que é precedido mediante a aprovação ou não aprovação de projetos de desenvolvimento e produção deles. Cuida-se, pois, de medida típica de disciplina pública da empresa privada (11): em razão do interesse público - que, no caso, coincide com o interesse social - as empresas do setor ficam sujeitas a controle mediante autorização do poder público.

Reserva-se às empresas nacionais, assim, o mercado da produção - e comercialização - de bens de informática no Brasil (12).

08. O conceito legal de empresa nacional (definição estipulativa), e enunciado no artigo 12 da Lei 7.232/84, acima transcrito.

Este artigo toma três elementos como característicos da empresa nacional: há de ser pessoa jurídica; há de ter sido constituída e ter sede no Brasil; o controle dela há de estar, em caráter permanente, exclusivo e incondicional, sob a titularidade, direta ou indireta, de pessoas físicas residentes e domiciliadas no Brasil ou de entidades de direito público interno.

Considerada a circunstância de ser polissêmico o vocábulo controle, esse mesmo artigo 12 precisou o seu significado no texto e para os efeitos da Lei $\mathrm{n}^{\mathrm{Q}}$ 7.232/84.

Assim, além de distinguir entré controle decisório, controle tecnológico e controle de capital, tem como descaracterizada a situação de controle direto ou indireto por pessoas físicas residentes e domiciliadas no Brasil ou por entidades de direito público interno quando não sejam elas titulares de um apenas deles.

Vale dizer: esses três tipos de controle têm substância própria, autonomia; não há subordinação entre um e outro; um não deriva dos outros. Logo, para que uma empresa deixe de ser entendida como empresa nacional, para os efeitos da Lei $\mathrm{n}^{\mathrm{Q}} 7.232 / 84$, basta que a titularidade de qualquer daqueles controles - decisório, tecnológico ou de capital não seja detido, em determinado momento, direta ou indiretamente, por pessoas físicas residentes e domiciliadas no Brasil ou por entidades de direito público interno.

Assim, é certo que se o controle tecnológico de determinada empresa, pessoa jurídica constituída e com sede no Brasil, não estiver sob a titularidade direta ou indireta de pessoas físicas residentes e domiciliadas no Brasil ou de entidades de 
direito público interno - ainda que os controles decisórios e de capital estejam sob a titularidade de umas ou outras - essa não poderá ser entendida, para os efeitos da Lei $\mathrm{n}^{\mathrm{9}} 7.232 / 84$, como empresa nacional.

09. Os incisos I e III do sempre referido artigo 12 definem, respectivamente, controle decisório e controle de capital.

No inciso II, que nesta oportunidade mais importa conhecer a definição legal de controle tecnológico: "o exercício, de direito e de fato, do poder para desenvolver, gerar, adquirir e transferir e variar de tecnologia de produto e de processo de produção".

Note-se, ademais, que o caput do artigo 12 exige que o controle inclusive o controle tecnológico esteja sob a titularidade das pessoas 'e entidades que refere em caráter permanente, exclusivo e incondicional.

Temos, destarte, que para que a pessoa jurídica constituída e com sede no Brasil seja entendida como empresa nacional, para os efeitos da Lei $\mathbf{n}^{\mathrm{Q}} 7.232 / 84$, além de os seus controles decisório e de capital estarem em caráter permanente, exclusivo e incondicional sob a titularidade direta ou indireta da pessoas ou entidades indicadas no seu artigo 12 , é necessário que pessoas ou entidades como tais exerçam, de direito e de fato, em caráter permanente, exclusivo e incondicional, o poder para desenvolver, gerar, adquirir e transferir e variar de tecnologia de produto e de processo de produção.

O controle tecnológico a que respeita o inciso II do artigo 12 da Lei $n^{2}$ $7.232 / 84$ configura modalidade de controle externo, ou seja, de influência dominante, que pode ser exercida por meios diversos do voto.

O que pretende o texto legal é a manutenção, em caráter permanente, exclusivo e incondicional, do poder a que refere, em seu exercício de direito e de fato, direta ou indiretamente, por pessoas físicas residentes e domiciliadas no Brasil ou por entidades de direito público interno. Observo que, embora o texto legal qualifique o controle como exercido, de direito e de fato, em caráter permanente, exclusivo e incondicional, alude a um estado (verbo estar) e não a uma situação de permanência, que respeite à estrutura da empresa. Assim, fundamental é que a empresa esteja sob controle - controle decisório, controle tecnológico e controle de capital direto ou indireto, de tais pessoas ou entidades.

Essa a finalidade do preceito normativo, .cujo conteúdo pleno há de ser discernido mediante a consideração também da norma-objetivo contemplada no artigo $3^{2}$ da Lei $n^{2} 7.232 / 84$.

Logo - não será demasiado repetí-lo - tratando-se do controle tecnológico, é imprescindível, para que a pessoa jurídica possa ser entendida como empresa nacional, para os efeitos da Lei $\mathrm{n}^{\mathfrak{Q}} 7.232 / 84$, que pessoas físicas residentes e domiciliadas no Brasil ou entidades de direito público interno exerçam, direta ou indiretamente, em relação a ela, de direito e de fato, em caráter permanente, exclusivo e incondicional, o poder para desenvolver, gerar, adquirir e transferir e variar de tecnologia de produto ou de processo de produção ${ }^{(13)}$. 
10. Um dos problemas mais debatidos, em torno da aplicação do conceito legal de empresa nacional, respeita ao seguinte fato: empresas- nacionais que celebrem contratos de joint ventures personalizadas (as equity joint ventures do direito norte-americano) ou de consórcio com empresa não nacional permanecem sendo entendidas, para os efeitos da Lei $n^{\circ} 7.232 / 84$, como empresas nacionais? ${ }^{(13)}$

Em ambos os casos da joint venture personalizada e do consórcio - os sócios ou acionistas e os contratantes colaboram entre si, tendo em vista a realização de um empreendimento comum.

Os contratos de sociedade e de consórcio consubstanciam contratos de comunhão de escopo, ao passo que o contrato de transferência de tecnologia consubstancia contrato de' intercâmbio, ainda que o preço recebido pelo cedente esteja sujeito a álea (percentual sobre as vendas do adquirente da tecnologia).

Essa distinção, equácionou-a já Von Thering ${ }^{(14)}$.

Nos contratos de intercâmbio os interesses das partes estão em contraposição, polarizados. Cada parte persegue os seus próprios interesses; quanto mais desvantajosa for a compra para o comprador, mais vantajosa será para o vendedor, e vice-versa. A política de cada parte pode ser sumariada na seguinte frase: o prejuízo dele é meu lucro (sein Schaden mein Gewinn).

Nos contratos de comunhão de escopo Von Thering refere-se aos contratos de sociedade os interesses dos contratantes são paralelos. Se um dos contratantes sofre prejuízo, os outros também o suportam. Da solidariedade de interesses que o caracteriza, o lema: a vantagem dele é a minha vantagem, minha vantagem é a sua vantagem (sein Vorteil mein Vorteil, mein Vorteil sein Vorteil).

A distinção, em verdade, fora já discernida por Grócio, no século XVII, como observa Ascarelli (15): os contratos de intercâmbio dirimunt partes, os contratos de escopo communionem adferunt.

Se, nos contratos de intercâmbio, o elemento fundamental é o sinalagma vínculo de recíproca dependência entre as obrigações do contrato bilateral - na sociedade e no consórcio o elemento fundamental é o escopo (objetivo) comum ${ }^{(16)}$. Daí a observação, ainda de Von Thering: o contrato de intercâmbio tem por pressuposto a diversidade, enquanto que o contrato de sociedade - contrato de comunhão de escopo - a identidade de objetivo ${ }^{(17)}$.

Os subsídios até este ponto alinhados me permitem afirmar que, sem sombra de dúvida, a constituição de joint venture e a celebração de contrato de consórcio tecnológico conduzem à transferência, de fato - ainda que isso, de direito, não seja assim assumido - do controle tecnológico para a parte que empresta tecnologia à execução do empreendimento comum. Se e quando a prestadora de tecnologia for pessoa jurídica estrangeira, a esta, que a presta ao empreendimento comum: o sócio ou consorciado nacional torna-se dependente da capacidade tecnológica do outro sócio ou consorciado.

Estamos, em ambas as hipóteses, diante de contrato de comunhão de escopo que supõe no caso - no prestador de tecnologia, poder no mínimo suficiente para influir nas decisões relativas ao desenvolvimento, à geração, à aquisição e transferência e variação de tecnologia de produto e de processo de produção. Se assim não for não teremos, no caso, caracterizada a constituição de joint venture ou a 
celebração de contrato de consórcio. Não se terá configurada a busca da realização de empreendimento comum, a identidade de objetivo.

A constituição de joint venture personalizada e a celebração de consórcio portanto, no caso, não podem deixar de levar, no mínimo, à atribuição de influência, ao prestador de tecnologia, em relação a tais decisóes, o que compromete o exercício, de fato, direto ou indireto, pelas pessoas ou entidades indicadas no artigo

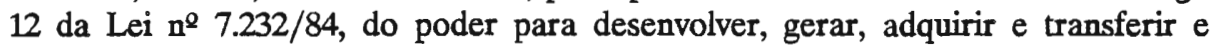
variar tecnologia de produto e de processo de produção. A tecnologia não é transferida, mas emprestada pela empresa estrangeira à realização do empreendimento comum.

Pouco importa a forma de configuração de joint venture. Em qualquer hipótese, o detentor da tecnologia aplicada ao empreendimento comum exercerá poder de influência sobre a pessoa jurídica. Esta, destarte - porque o exercício, de fato, do poder para desenvolver, gerar, adquirir e transferir e variar de tecnologia de produto e de processo de produção não estará, em caráter permanente, exclusivo e incondicional, direta ou indireta, sob a titularidade das pessoas e entidades indicadas no artigo 12 da Lei n⿳⺈ 7.232/84 - não poderá ser entendida como empresa nacional, para os efeitos desta última. A dinâmica do poder no interior dos contratos de comunhão de escopo, nos quais as partes concorrem para a realização de um mesmo objetivo, supõe - em especial quando se trate de contratação do tipo (joint venture e consórcio tecnológicos) - indispensável e necessária de quem presta a tecnologia ao empreendimento em relação às decisões, da pessoa jurídica, atinentes ao desenvolvimento, à geração, à aquisição, à transferência e à variação de tecnologia do produto e de processo de produção ${ }^{(18)}$. E fora de dúvida que, embora essa influência possa vir a ser de direito dissimulada na contratação, a admitir-se, para argumentar, que o co-venture ou o co-consorciado detentor da tecnologia não a exerçam de fato, teremos que um e outro não estarão colaborando para a realização de empreendimento comum. Não se terá, então, contrato de comunhão de escopo. Caracterizadas no entanto as joint ventures personalizadas e os consórcios tecnológicos como modalidades de colaboração entre empresas, em razão da identidade de objetivo - sein Vorteil mein Vorteil, mein Vorteil sein Vorteil - tem-se como presumido juris et de jure, nelas, o exercício, de fato, pelo co-venture ou pelo co-consorciado, de influência sobre o controle tecnológico do empreendimento comum.

11. A constitucionalidade da reserva de mercado e do conceito legal, da Lei n 7.232/84, de empresa nacional é incontestável.

O princípio da liberdade de iniciativa econômica, consagrado no texto da hoje vigente Constituição brasileira, não é ferido mediante a institucionalização da reserva de mercado. Observe-se, inicialmente, que não há limitações ao direito de liberdade econômica, mas tão-somente à liberdade econômica, visto que o princípio e o regime de liberdade econômica são aqueles definidos pela ordem jurídica. Vale dizer: o direito de liberdade econômica só tem existência no contexto de cada ordem jurídica, tal como definiu esta ordem jurídica. O exercício da liberdade de iniciativa econômica só é possível quando autorizado pela ordem jurídica, nos limites dessa 
autorização. Além de tais limites não há, obviamente, direito de liberdade econômica.

No caso, o controle das atividades de informática e a reserva de mercado, tal como instituídos na Lei $n^{\mathbb{Q} 7.232} / 84$, instrumentam a realização do desenvolvimento nacional, um dos fins da ordem econômica expressamente referido no hoje vigente texto constitucional brasileiro (norma-objetivo do ser artigo 160).

Também a enunciação de um conceito legal de empresa nacional pela Lei $\mathrm{n}^{\mathbf{Q}}$ 7.232/84 não é incompativel com a hoje vigente ordem constitucional, visto que inteiramente adequado ao ideal de busca do desenvolvimento nacional.

De resto, além de ser flagrante a desigualdade entre empresas nacionais e empresas não nacionais, tal como concebidas pela Lei $\mathrm{n}^{\circ} 7.232 / 84$, desigualdade decorrente de características que nelas residem o que justifica e fundamenta tratamento discriminatório, em favor das empresas nacionais, que lhes atribui a lei o princípio da igualdade, como observa Fábio Konder Comparato, em texto inédito, não é, entre nós, extensível às pessoas jurídicas. Esse princípio é inerente às pessoas naturais e a Constituição vigente entre nós, ao contrário da Constituição da República Federal da Alemanha artigo 19, alínea 3 não o faz alcançar as pessoas jurídicas.

Finalmente, relembre-se que, além de o direito positivo brasileiro consagrar algumas modalidades de reserva de mercado, tais como as que alcançam as atividades jornalísticas de qualquer espécie, inclusive de televisão e de radiodifusão, a atividade de navegação de cabotagem e, parcialmente, as atividades das instituições financeiras, outras, à margem dele subsistem - tal como a aplicável ao setor da indústria automobilística - sem nenhuma contestação, em especial das CMNs.

A reserva de mercado instituída pela Lei $\mathrm{n}^{0} \mathbf{7 . 2 3 2} / 84$, insisto, instrumenta a modernização do capitalismo nacional e, por isso mesmo, é plenamente compatível com os seus princípios. Daí porquê as investidas de toda ordem contra ela assacadas partem sempre das CMNs, ainda que envolvendo setores econômicos nacionais mais diretamente subordinados às açōes do capitalismo internacional. $O$ episódio da retaliação das exportaçōes brasileiras, ameaça com que acenam os Estados Unidos, é bastante expressiva: o preço da "proteção" por eles conferida a nossa economia de exportação seria o da revogação da reserva de mercado.

12. Devo porém observar que, ao tempo em que este texto está sendo escrito, reune-se, no Brasil, uma Assembléia Nacional Constituinte, sem que o título da ordem econômica tenha, até então, sido votado.

Pressões de toda ordem são desencadeadas sobre ela e, significativamente, muitas na tentativa de introduzir conceitos da empresa nacional que inviabilizem a eficácia da Política Nacional de Informática. Muito em breve saberemos da capacidade nacional de resistência diante das imposições das CMNs e do capitalismo internacional ${ }^{(19)}$.

IV - Os efeitos da Política Nacional de Informática e, especialmente, da reserva de mercado neste setor da economia brasileira. 
13. A institucionalização de uma Política Nacional de Informática e, especialmente, da reserva de mercado, entre nós, gerou efeitos extremamente positivos.

Ainda que o País não se tenha libertado de todo da dependência em relação à CMNs e à tecnologia internacional, essa dependência se transformou ${ }^{(20)}$.

Em termos quantitativos, aquela instituição possibilitou o surgimento de quantrocentas empresas nacionais no setor, com um faturamento de 1.5 bilhão de d6́lares norte-americanos no ano de 1986. A participação no mercado nacional, dessas empresas, é superior a cinqüenta por cento, situação apenas superada pela dos Estados Unidos e do Japão. Por outro lado, dos empregos diretos gerados, um terço deles é ocupado por profissionais de nível superior, situação também excepcional em uma economia não desenvolvida.

Em termos qualitativos, a engenharia nacional encontrou vias de inserção na atividade de concepção de tecnologias e, dar, verificou-se tambem o surgimento de marcas nacionais. Permitiu o surgimento e a expansão de competências técnicas exercitando atividades anteriormente inexistentes ou meramente embrionárias, economicamente insignificantes. $E$ mais, ensejou o desenvolvimento do efeito "mecatrônico" (acoplagem da mecânica com a eletrônica), dando lugar à ampliação das possibilidades de inovação a partir da interação entre diversas tecnologias de produto e de processamento industrial.

O País encontra um caminho firme para a conquista de autonomia, entendida esta, aqui, como a capacidade de tomar decisōes e adotar valores próprios. Onde apenas havia usuários de tecnologia passam, agora, a atuar concebedores dela. Essa capacidade, de criação de tecnologias, é um dos pressupostos daquela autonomia. Daí porque o poder das CMNs, de impor suas decisōes sobre a nossa economia, é relativamente reduzido.

Tudo poderia ser resumido, singelamente, em duas afirmações: verifica-se uma metamorfose em nossa situação de dependência; a evidência de que essa metamorfose é favorável ao interesse nacional é atestada pelas pressões que as CMNs e os países de economia desenvolvida desencadeiam contra a Política Nacional de Informática e, especialmente, contra a reserva de mercado.

\section{Notas:}

1. Agradeço a Claúdio Zamitti Mammana não apenas a oportunidade de termos debatido longamente o tema desta parte da presente exposição - como assim daquela referente aos efeitos da Política Nacional de Informática - mas também o acesso ao texto, não publicado, de sua conferência na Universidade de Londres, em outubro de 1984 (Transfer of technology in the field of informatics - the brazilian case).

2. Habermas, $I$ discorso filosofico della modernità, trad. di Emilio Agazzi, seconda edizioni, Editori Laterza, Roma, 1988, p. 2.

3. Conferência citada na nota 1. 
4. Eros Roberto Grau, Direito, conceitos e normas jurídicas, Ed. Revista dos Tribunais, São Paulo, 1988, pp. 123/130. Para uma visualização dessas normas como instrumento de transformação das lutas sociais em um jogo - o jogo capitalista - vide p. $17 / 18$.

5. Peter Evans, Informática - a metamorfose da dependência, trad. de Paulo Lopes e Kevin Mundy, in Novos Estudos, Cebrap, $\mathrm{n}^{\mathcal{2}}$ 15, julho de 1986, p. 14 e ss. e Emanuel Adler, Ideoligical "guerrillas" and the quest for technological autonomy: Brazil's domestic industry, in International Organization, Summer 1986, p. 673 e ss. nota 1.

6. A expressão é de Claúdio Zamitti Mammana, in conferência citada na

\section{7. p. 22.}

8. Daí, inclusive, a emenda de 1984 no Trate Act norte-americano (Seç̧ão 301).

9. Der Zewck in Recht, Druk und Berlag von Britkopt \& Hartel, Erster Band, zweite umgearbeitete auflage, Leipzig, 1884, p. VII. pp. $130 / 153$.

10. A propósito da noção de norma-objetivo, Eros Roberto Grau, ob. cit.,

11. Massimo Severo Giannini, Diritto pubblico dell'economia, Il Mulino, Bologna, 1977, p. 175 e ss e Vincenzo Spagnuolo Vigorita, Attivitá economica privata e potere amnistrativo, I Romano Editore, Pompei, 1962, p. 193 e ss. $7.646 / 87$.

12. A comercialização do software é objeto de regulação pela Lei $n^{\mathcal{Q}}$

13. Cuida-se de saber, no primeiro caso, se a joint venture personalizada pode ser entendida como empresa nacional.

14. ob. cit., p. $212 / 213$.

15. Problemas das sociedades anônimas e Direito Comparado, $2^{\mathrm{a}}$ edição, Saraiva, São Paulo, 1969, p. 255.

16. Fábio Konder Comparato, Ensaios e pareceres de Direito Empresarial, Forense, Rio de Janeiro, 1978, p. 137 e Novos ensaios e pareceres de Direito Empresarial, Forense, Rio de Janeiro, 1981, p. 44.

17. ob. cit., p. 208. 
18. Luiz Olavo Baptista et Pascal Durand-Barthez, Les Associations D'Entreprises (Joint Ventures) dans le Commerce International, FEDUCI-L.G.D.J, Paris, 1986, p. 56.

19. A fim de que se possa ter uma tênue idéia da intensidade dessas pressões, que são desencadeadas sem nenhum refinamento, observo que uma das emendas do projeto de texto constitucional singelamente propõe a supressão de disposição que estabelece que "o Estado e as entidades da administração direta e indireta privilegiarão a capacitação científica e tecnológica nacional como critérios para a concessão de incentivos, compras e acesso ao mercado brasileiro" (destaque 1532 ao parágrafo único do artigo 254 do projeto).

20. Peter Evans, ob. cit. p. 24.

São Paulo, 12 de setembro de 1988. 